\title{
A biologging technique for monitoring the egg-releasing behavior of Pacific abalone Haliotis discus hannai in the wild
}

\author{
Yukio Matsumoto ${ }^{1, *}$, Kousuke Yatsuya $^{1}$, Ayumi Nakatsubo ${ }^{1,2}$, Hideki Takami $^{3}$ \\ ${ }^{1}$ Miyako Laboratory, Tohoku National Fisheries Research Institute, Japan Fisheries Research and Education Agency, Miyako, \\ Iwate 027-0097, Japan \\ ${ }^{2}$ Faculty of Agriculture, Yamagata University, Yamagata 990-8560, Japan \\ ${ }^{3}$ Shiogama Laboratory, Tohoku National Fisheries Research Institute, Japan Fisheries Research and Education Agency, \\ Shiogama, Miyagi 985-0001, Japan
}

\begin{abstract}
To examine causes of variation in the population dynamics of Ezo abalone Haliotis discus hannai, it is important to understand its reproductive behavior, but there have been no methods for analyzing behavior related to egg release in the field. Spawning is assumed to occur in response to stormy weather, but this hypothesis remains untested. In the laboratory (August $2014)$, the behavior of abalone from Iwate Prefecture, northeastern Japan $\left(39^{\circ} 36^{\prime} \mathrm{N}, 142^{\circ} 2^{\prime} \mathrm{E}\right)$ was recorded using 3-axis acceleration data loggers. Egg-releasing behavior was characterized using the predominant frequencies and amplitudes of time series acceleration data. Subsequently (October 2015), the putative egg-releasing behavior of abalone in the wild was recorded at the collection site, using the 3-axis acceleration data loggers. Further field observations using this system on $H$. discus hannai and other abalone species are expected to facilitate identification of the principal factors stimulating abalone spawning.
\end{abstract}

KEY WORDS: Abalone $\cdot$ Reproductive behavior $\cdot 3$-axis acceleration data loggers

\section{INTRODUCTION}

To examine causes of variation in population dynamics of abalone species, it is important to understand their reproductive behavior. For instance, stormy weather conditions are known to affect the occurrence of juvenile abalone. In the abalone Haliotis diversicolor aquatilis, juveniles are not observed in years when typhoons do not impact the study areas, so typhoons have been suggested to induce spawning in this species (Onitsuka et al. 2007). Furthermore, the number of Haliotis discus hannai larvae was significantly correlated with wave height in one study (Sasaki \& Shepherd 2001). Although the mechanisms underlying variation in the scale of spawning has not been determined, the number of spawning individuals likely increases when a strong storm approaches

*Corresponding author: ymatsumoto@affrc.go.jp
(Sasaki \& Shepherd 2001). Abalone larvae are lecithotrophic and can swim for $\sim 20 \mathrm{~d}$ by consuming egg yolk when there is no suitable settlement place (Takami et al. 2002). A hydrodynamic and particletracking model demonstrated that storm scale affects the range of larval dispersal. Large-scale storms result in the larvae reaching unsuitable habitats (Miyake et al. 2009), but also remote populations (Miyake et al. 2011). In comparison, in small-scale storms, local spawning maintains the natal population (Miyake et al. 2011). Similar effects of larval dispersal on population dynamics have been reported for abalone species around the world, and differences in the timing of spawning could affect larval dispersal through the effects of hydrodynamics (Miyake et al. 2017). However, observations of abalone spawning behavior in the wild are limited (e.g. Breen \& Adkins

(C) The authors 2018. Open Access under Creative Commons by Attribution Licence. Use, distribution and reproduction are unrestricted. Authors and original publication must be credited. 
1980, Sloan \& Breen 1988, Stekoll \& Shirley 1993), and the environmental stimuli that trigger spawning remain unknown. A method is needed for continuous, long-term behavioral observation to identify spawning triggers.

The present study tested whether egg-releasing behavior of Ezo abalone H. discus hannai (Ino 1953) could be recorded using a 3-axis acceleration data logger. We also attempted to record egg-releasing behavior in the wild using the data logger.

\section{MATERIALS AND METHODS}

Haliotis discus are marine gastropods in the family Haliotidae. In Japan, $H$. discus consists of 2 subspecies: $H$. discus hannai (Ezo abalone) and $H$. discus discus (Ino 1953). Only H. discus hannai occurs at our study site in Iwate Prefecture, Japan (39 36' N, $142^{\circ} 2^{\prime}$ E) (Ino 1953, Hara \& Sekino 2005).

When combined with frequency analysis of acceleration data, 3-axis acceleration data loggers can be powerful tools for assessing various parameters of target organisms that cannot readily be directly observed by researchers (Sakamoto et al. 2009). In this study, we recorded the motion of $H$. discus hannai and tested whether egg-releasing behavior can be characterized by changes in the acceleration data. First, time series acceleration data during eggreleasing behavior was recorded in a tank $(300 \times 195$ $\times 205 \mathrm{~mm}$ ) using a 3-axis acceleration data logger and video camera. Second, these data were characterized by examining the predominant frequencies and amplitudes of acceleration. Third, we tested whether the egg-releasing behavior in the trial data could be extracted using the characteristics of the 3 -axis acceleration data. Details of each stage are presented in the subsequent sections. This study was performed in accordance with the guidelines for ethological studies by the Japan Ethological Society (www.ethology.jp/guideline.pdf).

\section{Data collection}

We built a 3 -axis data logger $(10 \mathrm{~Hz}, \pm 2 \mathrm{~g}$ range, $12-$ bit resolution, width $\times$ length $\times$ height: $3.9 \times 6.9 \times$ $1.6 \mathrm{~cm}$, weight in air: $45 \mathrm{~g}$, weight in water: $3.9 \mathrm{~g}$; Fig. 1a) based on Arduino (https://www.arduino.cc/). Together with a video camera (DVSA10FHDIR; Kenko
Tokina Corporation), we recorded the egg-releasing behavior of female abalone on 12, 19, and 26 August 2014. We did not test whether the volume of the 3 -axis data logger affected the behavior of abalone in the wild, but its impact on the behavior of abalone under tank conditions with no flow was considered minimal. Egg-releasing behaviors were validated based on the video data, and the acceleration data recorded during this behavior were used in our analysis. A plastic frame for mounting the logger was attached to the abalone shells using epoxy resin. The data logger was mounted onto the plastic frame using cable ties, before behavioral recording (Fig. 1a). Female egg-releasing behavior was induced by immersing the abalone in sea water and exposing them to high levels of ultraviolet light (800 $\mathrm{MWh}^{-1}$ ). Egg-releasing behavior usually starts 1-3 h after exposure to ultraviolet light (Uki \& Kikuchi 1974). Although male abalone do not actively move their shells during sperm release (Video S1 in the Supplement at www.int-res.com/articles/suppl/ b027p119_supp/), females move their shells up and down several times over periods of several 10s of seconds to release the eggs (Video S2). We regarded this sequence of egg release as a single egg-releasing behavior. The egg-releasing behavior was often repeated several times, at intervals of about $10 \mathrm{~min}$ in the tank. This study recorded a total of 54 egg releases from 9 females (mean $\pm \mathrm{SD}$; shell length [SL]: $10.29 \pm 0.48 \mathrm{~cm}$, weight: $162.83 \pm 22.77 \mathrm{~g}$ ). During egg release, the shell moved slowly upward at its head and then pulled quickly down, twisting radially (Fig. 1b,c). Therefore, we concluded that egg-releasing behavior could be recorded tri-axially ( $x$-axis, $y$-axis, and $z$-axis).

\section{Data analysis}

Because the acceleration data during egg release has a characteristic pattern, egg- releasing behavior 
may be identified and extracted accordingly from the repetition of this pattern of events. However, an index that objectively indicates egg-releasing events is necessary. As a method of characterizing specific acceleration data corresponding to specific behavior, the predominant frequency and amplitude of the acceleration data are often calculated in biologging studies (e.g. Sakamoto et al. 2009). The acceleration data were analyzed using Ethographer (https://sites. google.com/site/ethographer/docs), software that works with IGOR Pro (WaveMetrics) as the graphical user interface (GUI).

For this analysis, the acceleration data were regarded as waveforms. First, we chose the acceleration data of egg-releasing events based on the video data. The frequency and amplitude of the multiple waveforms that occurred in the acceleration data were calculated using Continuous Wavelet Transform (CWT; see also Sakamoto et al. 2009). In these analyses, the Morlet wavelet function (the coefficient of Morlet mother wavelet is 5) with a minimum frequency of $0.1 \mathrm{~s}$ and a maximum frequency of $30 \mathrm{~s}$ was used. CWT analysis was performed by dividing the data for each $1 \mathrm{~h}$ period. The time series acceleration data after wavelet transformation were presented as a scalogram to clarify the frequencies and amplitudes of the multiple waveforms in the acceleration data in each period (Fig. 2a-c). Subsequently, the part with the highest amplitude was extracted for each time period (white lines in Fig. 2a-c). The part traced by the white line was regarded as the dominant frequency in each time period. The frequencies and their highest amplitudes at the center points of each egg-releasing behavior are presented as a power spectrum (Fig. 2d-f). The frequency with the highest amplitude in the power spectrum agrees with the frequency and amplitude at the point where the white line and pink line intersect in the scalogram (Fig. 2a-c). The frequency with the highest amplitude was read from the power spectrum and defined as the predominant frequency in the egg-releasing behavior.

The predominant frequencies and amplitudes of all spawning data were clarified. Then, the ranges of these predominant frequencies and their amplitudes were defined as the waveform characteristics during egg-releasing behavior (egg-releasing wave).

\section{Development of extraction methods}

We tested whether the egg-releasing behavior could be discriminated by extracting the egg-releas- ing waves from the time series of the 3-axis acceleration data. Thirty egg-releasing behaviors were randomly selected as trial data (length $1 \mathrm{~h}$ ) from the data set that was used to define the egg-releasing wave (54 egg-releasing behaviors of 9 females). The trial data were analyzed using CWT with the stated setting (the coefficient of Morlet mother wavelet $=5$, range of frequency $=0.1-30.0 \mathrm{~s}$ ) to clarify the predominant frequencies and their amplitudes in each time period. The range of egg-releasing waves was extracted from 3-axis acceleration data (see Fig. 4b, black bars). Finally, the periods when the egg-releasing waves were identified on all 3 axes were judged to represent egg-releasing behavior. These periods were verified from the data showing actual eggreleasing behavior.

We also attempted to record the egg-releasing behavior of free-ranging females using the data loggers. Test females were captured at a fishing ground in Iwate Prefecture, northeastern Japan, and were kept in a tank for approximately $2 \mathrm{wk}$. Five females with ripe gonads visible through their shells were fitted with data loggers (Fig. 1a) and were then released at 09:00 $\mathrm{h}$ on 6 October 2015 at the fishing ground. The females were released by SCUBA divers at $\sim 3 \mathrm{~m}$ depth. On 15 October, 2 females with data loggers (SL: 11.50 and $10.6 \mathrm{~cm}$; weight: 238 and $164 \mathrm{~g})$ were recaptured by SCUBA divers near the release site. In total, 67 and $49 \mathrm{~h}$ of data were obtained from the 2 recaptured females, respectively. The remaining 3 females (SL: 11.20, 10.00, and $9.4 \mathrm{~cm}$ ) were not recaptured.

\section{RESULTS}

The shell of the female abalone moves vertically during egg release (Fig. 1b,c). Acceleration on the $x-, y-$, and $z$-axis changed simultaneously during egg-releasing events, with these accelerations having specific frequencies ( $x$-axis, 4.9-11 $s_{i} y$-axis, 1-12.3 s; z-axis, 1.5-11.5 s; Fig. 3a) and amplitudes $(x$-axis, $\quad 0.076-0.74 ; \quad y$-axis, $0.073-0.713 ; \quad z$-axis, 0.12-0.45; Fig. 3b). Fig. 4 presents an example of the trial data ( 7 egg releases) used in the discrimination test of the egg-releasing behavior. We were able to discriminate egg-releasing behavior from the acceleration data of trials that were used to generate the egg-releasing waves (red arrows in Fig. $4 \mathrm{~b}$ ) and the timing was validated from the video data. Our method misidentified one creep behavior, which was verified from the video recording as eggreleasing behavior (blue arrow in Fig. 4b). Based on 
a

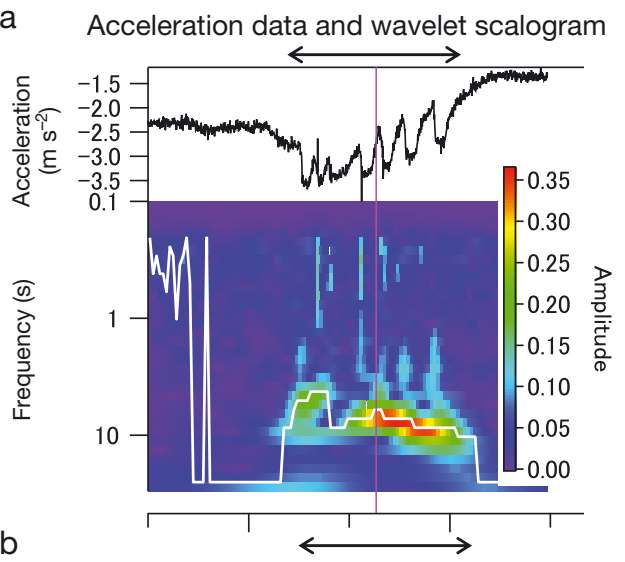

b
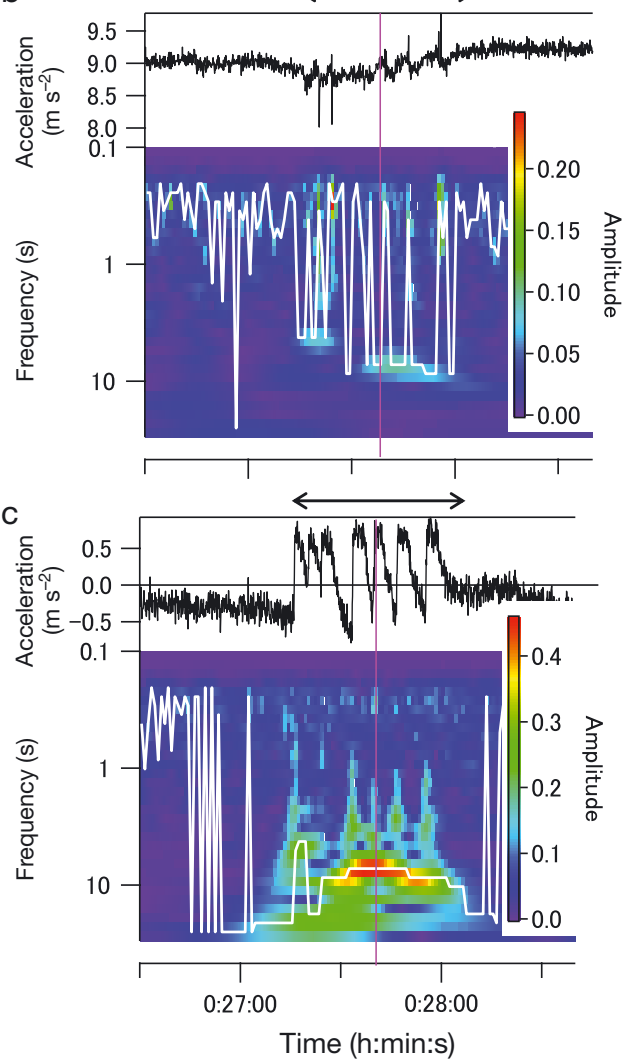

Dominant frequency and amplitude
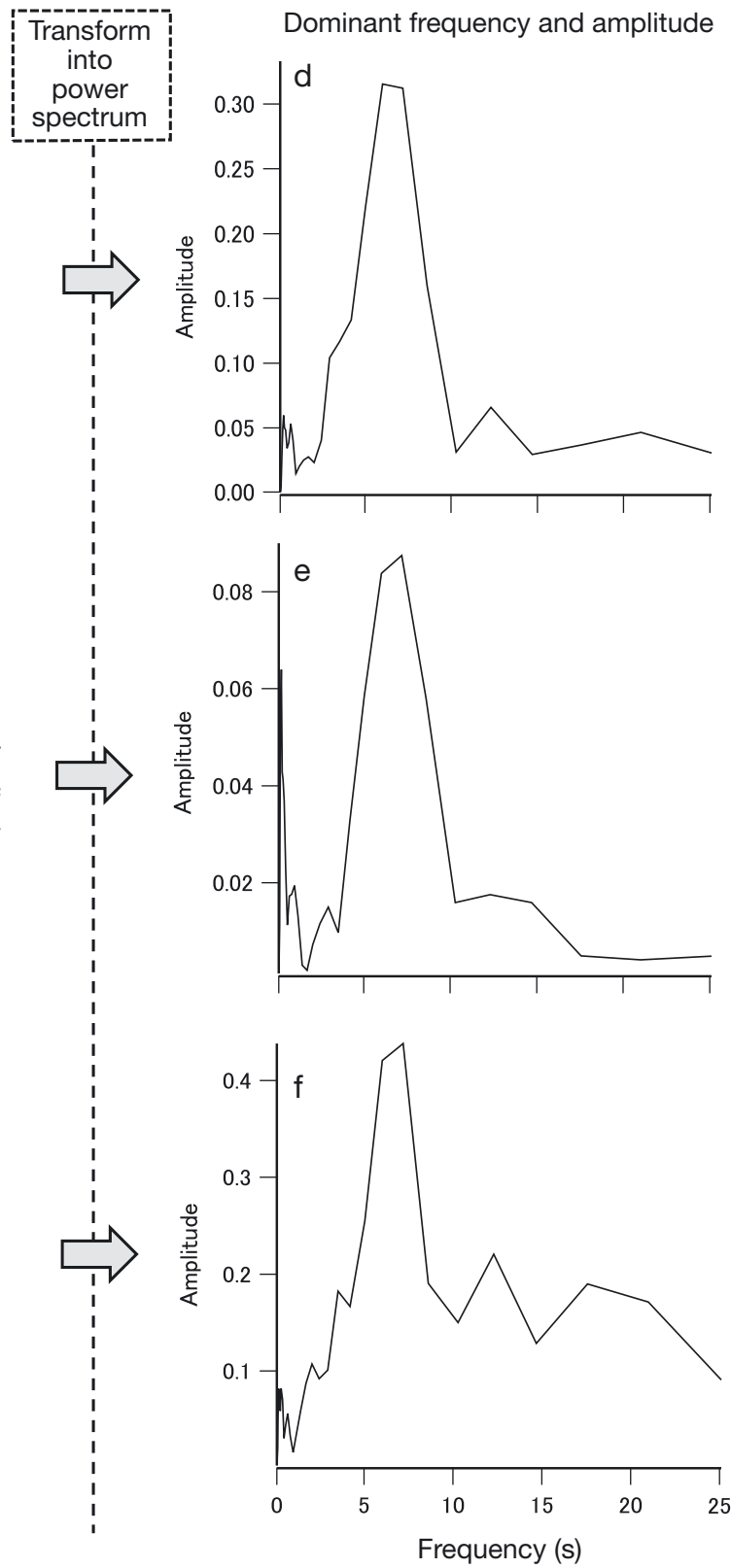

Fig. 2. Time series of acceleration data and scalogram of (a) $x$-axis, (b) $y$-axis, and (c) $z$-axis. White lines: dominant frequencies and their highest amplitudes in each time period; double-headed arrows: time period when female Pacific abalones released their eggs; pink lines: center point of egg-releasing behavior. Distribution of frequencies and highest amplitudes of waveforms included at center point of egg-releasing behavior on (d) $x$-axis, (e) $y$-axis, and (f) $z$-axis indicated as power spectrum
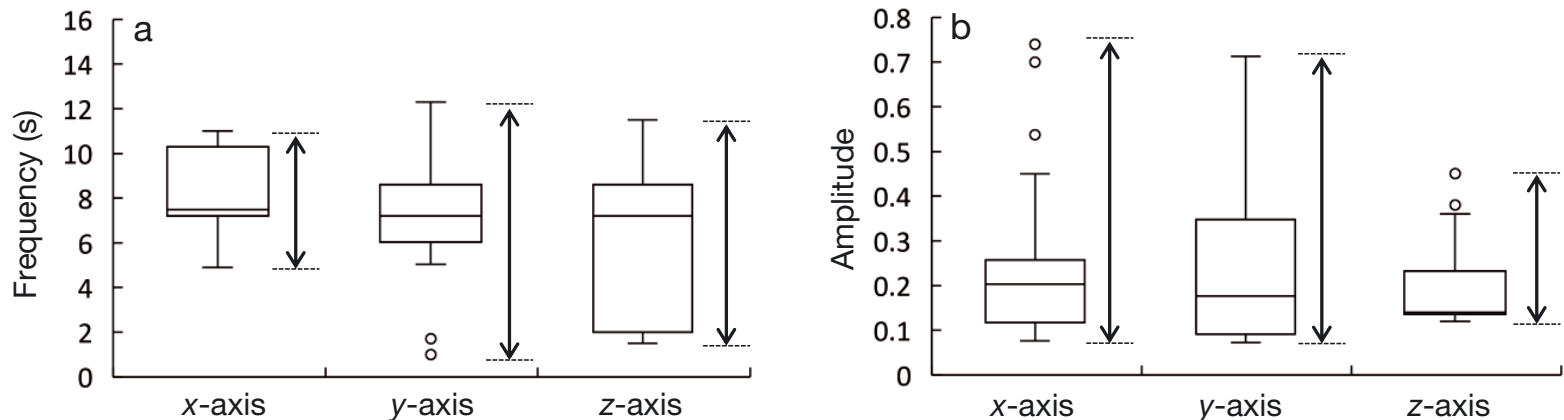

Fig. 3. Distributions of frequencies and amplitudes of time series acceleration data during Pacific abalone egg-releasing behavior. Data presented as boxplot diagrams showing medians (lines in the boxes), 25th and 75th percentiles (boxes), 10th and 90th percentiles (whiskers) and outliers (circles). The double-headed arrows indicate the range of the frequency and amplitude that are defined as characteristics of egg releasing 

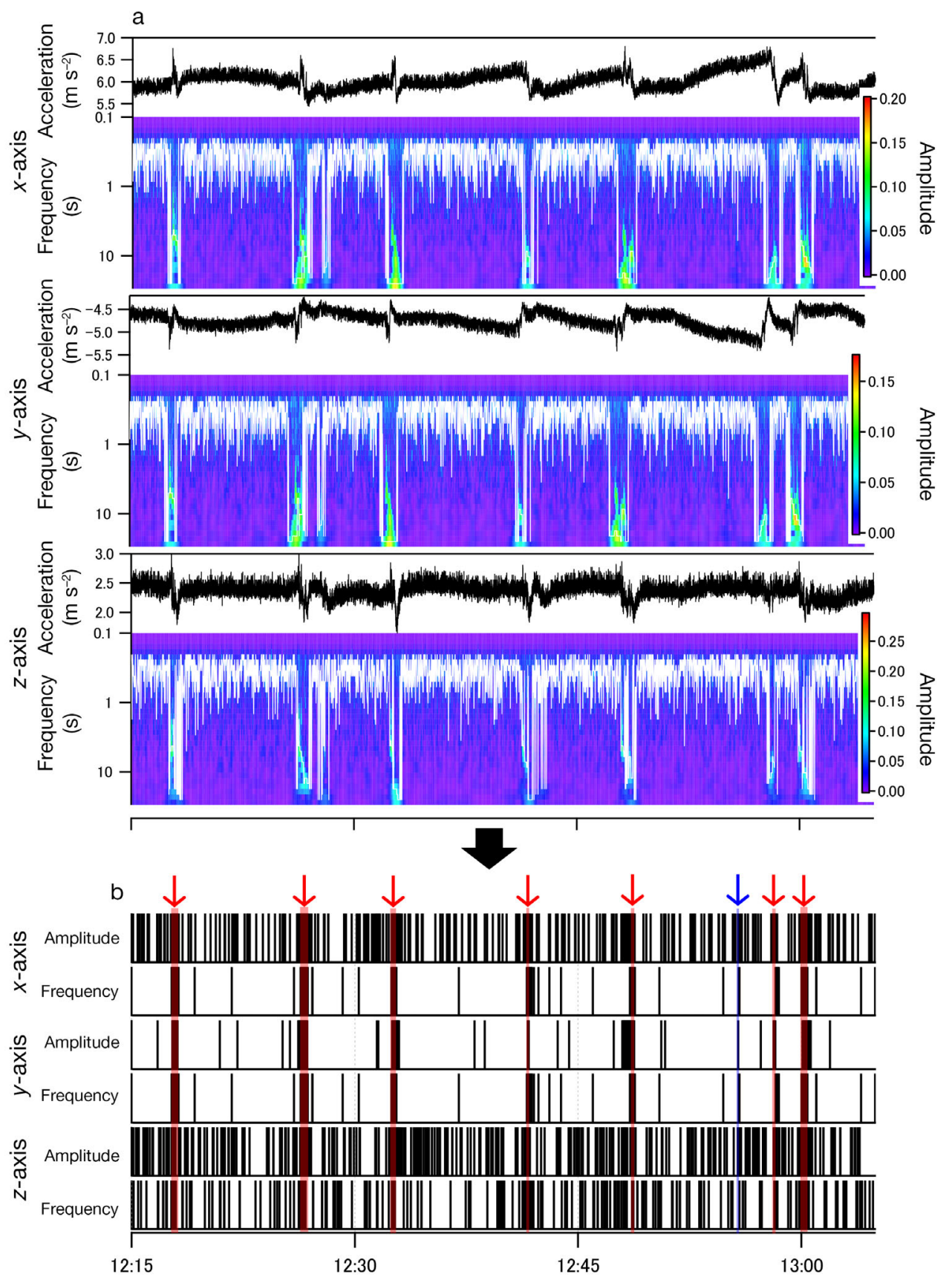

Fig. 4. Example of time series of acceleration data and scalogram of (a) $x$-axis, $y$-axis, and $z$-axis of trial data. White lines: predominant frequencies and their highest amplitudes during each time period. (b) Black bars: points with characteristics of Pacific abalone spawning based on frequencies and amplitudes for 3 axes. Red arrows and lightly filled areas: points where 6 black bars overlapped; these points represent time at which females actually released their eggs as validated by video recording. Blue arrow and lightly filled areas: points where factors overlapped but females did not release their eggs

this method, 25 of 30 actual egg-releasing behaviors were judged as egg-releasing behaviors. Just 5 eggreleasing behaviors were not judged as egg releasing behaviors. In other words, $96 \%(25 /[25+1])$ of the behavior discriminated as egg-releasing behavior from the trial data were actual egg-releasing behaviors, and $83 \%(25 /[25+5])$ of egg-releasing behaviors were extracted using this method from the trial data.

Acceleration data consistent with egg-releasing behavior in the tank (i.e. putative egg-releasing behaviors) were detected in the data retrieved from the 2 recaptured females from 11:45-12:40 h on 6 October (Fig. 5a,b). 


\section{DISCUSSION}

This study showed that spawning behavior can be discriminated readily and objectively by determining the dominant frequencies and amplitudes of time series acceleration during egg-releasing behavior of Haliotis discus hannai. Our methods can likely be applied to other abalone species because those females also move their shells during the egg release (e.g. H. diversicolor, Oba 1964; H. kamtschatkana, Sloan \& Breen 1988; H. discus discus, Ishida et al. 1991). To use these methods for other abalone species, the predominant frequencies of time series acceleration data and their amplitudes should be investigated in each species. In addition, since different Haliotis species vary in size, the most suitable size of logger should be tested for each species.

Putative egg-releasing behaviors were detected from the acceleration data recorded in the wild using the methods developed in this study. The number and time interval of putative egg releases are also essential criteria for validating whether putative eggreleasing behaviors are actually egg-releasing behaviors. Similar to the egg-releasing behaviors in the tank (Fig. 2), multiple putative egg-releasing behaviors were recorded about every $10 \mathrm{~min}$ (Fig. 5). In addition, the acceleration changes on the 3 axes were synchronized for about $30 \mathrm{~s}$ in wild abalone (expanded plots in Fig. 5) similar to our observations in the tank (Fig. 2a-c). These results indicate that putative egg-releasing behaviors recorded in the wild were likely assessed correctly.

This study indicated that the egg-releasing behavior of $H$. discus hannai could be characterized by the 3 -axis acceleration. It is possible that acceleration data accompanying unknown behavior in the wild is similar to the acceleration data consistent with eggreleasing behavior in the tank. Therefore, it will be necessary to record spawning behavior in the wild and to compare the video data with the acceleration data in order to verify that the putative egg-releasing behaviors recorded in the wild are actually eggreleasing behaviors. In addition, small loggers that minimally affect abalone behavior under stormy weather conditions should be used to reveal factors stimulating spawning. A decline in the population size of many abalone species has been documented globally (Cook 2016); thus, it is important to under-
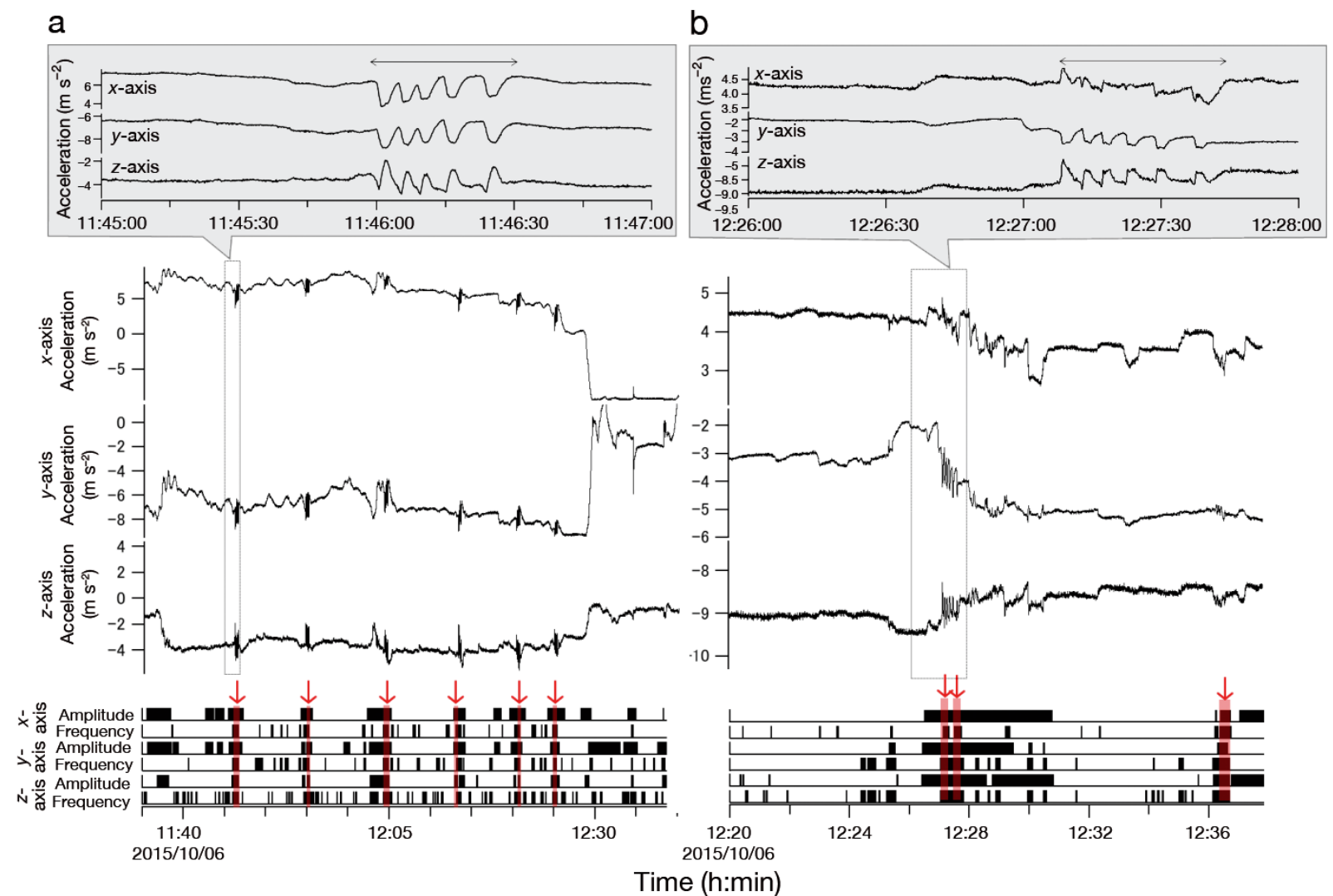

Fig. 5. Time series acceleration data of Pacific abalone (a) female 1 and (b) female 2, which released eggs on 6 October 2015. Red arrows and lightly filled areas: points where 6 black bars overlapped. Gray-filled panels: expanded plots of a part that identified egg-releasing behavior (occurring over the time period depicted by double-headed arrows) 
stand their spawning biology in the wild to manage wild populations effectively. The technique developed here to monitor the egg-releasing behavior using acceleration data loggers could be effective in providing new insights on the reproductive biology of abalone.

Acknowledgements. Messrs. Yuichi Kohsaka and Naoki Kimura of Omoe Fisheries Cooperative Association helped us carry out the field investigation. This study was supported by JSPS KAKENHI (15K18734) and Tohoku Ecosystem Associated Marine Sciences.

\section{LITERATURE CITED}

Breen PA, Adkins BE (1980) Spawning in a British Columbia population of northern abalone, Haliotis kamtschatkana. Veliger 23:177-179

Cook PA (2016) Recent trends in worldwide abalone production. J Shellfish Res 35:581-583

Hara M, Sekino M (2005) Genetic difference between Ezoawabi Haliotis discus hannai and Kuro-awabi $H$. discus discus populations: microsatellite-based population analysis in Japanese abalone. Fish Sci 71:754-766

Ino T (1953) Biological studies on the propagation of Japanese abalone (genus Haliotis). Bull Tokai Reg Fish Res Lab 5:1-102 (in Japanese)

Ishida O, Sakamoto Y, Takahashi H (1991) On the synchronism of spawning of Haliotis discus induced by UV irradiation. Suisan Zoshoku 39:375-379 (in Japanese)

Miyake Y, Kimura S, Kawamura T, Horii T, Kurogi H, Kitagawa T (2009) Simulating larval dispersal processes for abalone using a coupled particle-tracking and hydrodynamic model: implications for refugium design. Mar Ecol Prog Ser 387:205-222

Editorial responsibility: Judith Grassle, New Brunswick, New Jersey, USA
Miyake Y, Kimura S, Kawamura T, Kitagawa T, Takahashi T, Takami H (2011) Population connectivity of Ezo abalone on the northern Pacific coast of Japan in relation to the establishment of harvest refugia. Mar Ecol Prog Ser 440:137-150

Miyake Y, Kimura S, Horii T, Kawamura T (2017) Larval dispersal of abalone and its three modes: a review. J Shellfish Res 36:157-167

Oba T (1964) Studies on the propagation of an abalone, Haliotis diversicolor supertexta Lischke-II. On the development. Bull Jpn Soc Sci Fish 30:809-819 (in Japanese)

* Onitsuka T, Kawamura T, Horii T, Takiguchi N, Takami H, Watanabe Y (2007) Synchronized spawning of abalone Haliotis diversicolor triggered by typhoon events in Sagami Bay, Japan. Mar Ecol Prog Ser 351:129-138

Sakamoto KQ, Sato K, Ishizuka M, Watanuki Y, Takahashi A, Daunt F, Wanless S (2009) Can ethograms be automatically generated using body acceleration data from freeranging birds? PLOS ONE 4:e5379

Sasaki R, Shepherd SA (2001) Ecology and post-settlement survival of the Ezo abalone, Haliotis discus hannai, on Miyagi coasts, Japan. J Shellfish Res 20:619-626

Sloan NA, Breen PA (1988) Northern abalone, Haliotis kamtschatkana, in British Columbia: fisheries and synopsis of life history information. Publ Spec Can Sci Halieut Aquat 103:1-46

Stekoll MS, Shirley TC (1993) In situ spawning behavior of an Alaskan population of Pinto abalone, Haliotis kamtschatkana, Jonas, 1845. Veliger 36:95-97

Takami H, Kawamura T, Yamashita Y (2002) Effects of delayed metamorphosis on larval competence, and postlarval survival and growth of abalone Haliotis discus hannai. Aquaculture 213:311-322

Uki N, Kikuchi S (1974) Technical study on artificial spawning of abalone, genus Haliotis II. Effect of irradiated sea water with ultraviolet rays on inducing to spawn. Bull Tohoku Natl Fish Res Inst 33:79-86

Submitted: February 6, 2018; Accepted: September 18, 2018 Proofs received from author(s): October 27, 2018 